\title{
AN OBSERVATION CONCERNING BOUNDARY POINTS OF THE NUMERICAL RANGE
}

\author{
MARCEL HANSMANN
}

Abstract. A theorem of Hübner states that non-round boundary points of the numerical range of a linear operator, i.e. points where the boundary has infinite curvature, are contained in the spectrum of the operator. In this note, answering a question of Salinas and Velasco, we will show that Hübner's result remains true under the weaker assumption that the boundary has infinite upper curvature. Our short and simple proof relies on some classical ideas of Berberian.

Mathematics subject classification (2010): 47A10, 47A12.

Keywords and phrases: Numerical range, corners, infinite curvature.

\section{REFERENCES}

[1] S. K. Berberian, Approximate proper vectors, Proc. Amer. Math. Soc., 13: 111-114, 1962.

[2] S. K. Berberian AND G. H. ORLAND, On the closure of the numerical range of an operator, Proc. Amer. Math. Soc., 18: 499-503, 1967.

[3] W. F. Donoghue, JR., On the numerical range of a bounded operator, Michigan Math. J., 4: 261263, 1957.

[4] F. O. FARID, On a conjecture of Hubner, Proc. Indian Acad. Sci. Math. Sci., 109 (4): 373-378, 1999.

[5] M. Hansmann, On non-round points of the boundary of the numerical range and an application to non-selfadjoint Schrödinger operators, Journal of Spectral theory, to appear. ArXiv:1404.3960, 2014.

[6] S. HildebRAndT, Über den numerischen Wertebereich eines Operators, Math. Ann., 163: 230-247, 1966.

[7] M. HÜBNER, Spectrum where the boundary of the numerical range is not round, Rocky Mountain J. Math., 25 (4): 1351-1355, 1995.

[8] N. Salinas AND M. V. Velasco, Normal essential eigenvalues in the boundary of the numerical range, Proc. Amer. Math. Soc., 129 (2): 505-513 (electronic), 2001.

[9] I. M. SPITKOVSKY, On the non-round points of the boundary of the numerical range, Linear and Multilinear Algebra, 47 (1): 29-33, 2000.

[10] T. ZAMFIRESCU, Nonexistence of curvature in most points of most convex surfaces, Math. Ann., 252 (3): 217-219, 1980 